Board of Governors of the Federal Reserve System

\author{
International Finance Discussion Papers
}

Number 1118

September 2014

Offshoring, Mismatch, and Labor Market Outcomes

\author{
David M. Arseneau \\ Brendan Epstein
}

NOTE: International Finance and Discussion Papers are preliminary materials circulated to stimulate discussion and critical comment. References in publications to International Finance Discussion Papers (other than an acknowledgment that the writer has had access to unpublished material) should be cleared with the author or authors. Recent IFDPs are available on the Web at www.federalreserve.gov/pubs/ifdp/. This paper can be downloaded without charge from Social Science Research Network electronic library at www.ssrn.com. 


\title{
Offshoring, Mismatch, and Labor Market Outcomes*
}

\author{
David M. Arseneau ${ }^{\dagger} \quad$ Brendan Epstein ${ }^{\ddagger}$
}

September 8, 2014

\begin{abstract}
We study the role of labor market mismatch in the adjustment to a trade liberalization that results in the offshoring of high-tech production. Our model features twosided heterogeneity in the labor market: high- and low-skilled workers are matched in a frictional labor market with high- and low-tech firms. Mismatch employment occurs when high-skilled workers choose to accept a less desirable job in the low-tech industry. The main result is that-perhaps counter-intuitively - this type of job displacement is actually beneficial for the labor market in the country doing the offshoring. Mismatch allows the economy to reallocate domestic high-skilled labor across both high- and low-tech industries. In doing so, mismatch dampens both the increase in the aggregate unemployment rate and the decline in aggregate wages that come as a consequence of shifting domestic production abroad.
\end{abstract}

JEL Classification: F16, F66, J64.

Keywords: labor market frictions; globalization; trade liberalization; heterogeneous workers; search and matching.

\footnotetext{
*The views in this paper are solely those of the authors and should not be interpreted as reflecting the views of the Board of Governors of the Federal Reserve System or of any other person associated with the Federal Reserve System.

${ }^{\dagger}$ Board of Governors of the Federal Reserve System. 20th Street and Constitution Avenue N.W. Washington, D.C. 20551. Email address: david.m.arseneau@frb.gov.

${ }^{\ddagger}$ Board of Governors of the Federal Reserve System. 20th Street and Constitution Avenue N.W. Washington, D.C. 20551. Email address: brendan.epstein@frb.gov.
} 


\section{Introduction}

Improvements in transportation, information, and communication technologies over the past 30 years have led to greater internationalization of production processes. A key component of this aspect of globalization has been an increase in the willingness of firms to offshore - that is, to hire foreign workers to do jobs that were previously done domestically. ${ }^{1}$ One consequence of the increase in offshoring has been a backlash in public opinion regarding whether or not this trend is desirable. Indeed, offshoring - and, in particular, its impact on the labor market - is a controversial topic. The problem is all the more acute when we consider that the effects of offshoring may run beyond actual observed offshoring. Blinder (2009) makes the point that while actual offshoring may have an important effect on wages and employment, the mere fact that certain jobs have characteristics that make them susceptible to offshoring may also be an important driver of labor market outcomes.

There is a wide body of empirical evidence on the impact of offshoring on the labor market. ${ }^{2}$ However, it is difficult to extract a consistent theme at the aggregate level primarily because the wage and labor market effects tend to differ greatly depending on what specific notion of offshoring is being considered and on the degree of disaggregation of the data being studied. Indeed, no clear consensus emerges from these papers regarding whether or not a strong backlash against offshoring is, in fact, justified.

One relatively underdeveloped area of the literature concerns the role of trade and job dislocation, or the idea that high-skilled workers are forced into taking low-paying jobs. Earlier work by Jacobson, Lalond, and Sullivan (1993) and Kletzer (2001) suggests that job dislocation has an important role in the adjustment to globalization. More recently, work by Hummels, Munch, and Xiang (2011) uses Danish micro-level data to show that the adjustment costs for workers displaced due to offshoring tend to be higher than the

\footnotetext{
${ }^{1}$ The trend toward increased offshoring and more significant foreign involvement by multinational enterprises more generally is documented in Crino (2009), for example.

${ }^{2}$ For example, early work by Feenstra and Hanson (1996, 1997, and 1999) focuses on manufacturing offshoring, while Amiti and Wei (2005) and Gorg and Hansely (2005) focus on the rapid growth in services offshoring. These papers center primarily at the industry level. Taking yet a different approach, both Liu and Trefler (2008) and Ebenstein et al. (2011) try to measure the impact of offshoring using disaggregated data from the Current Population Survey (CPS). In still a different direction, Goos, Manning, and Salomons (2011) examine the link between offshoring and changes in the occupational structure of employment.
} 
adjustment costs for workers displaced for other reasons.

In this paper, we try to better understand the link between job dislocation and offshoring using a theoretical approach. Our analysis builds on Davidson, Matusz, and Shevchenko (2008) - henceforth DMS - which, in turn, is an open economy extension of Albrecht and Vroman (2002).

The model consists of two countries, called the North and South, each of which is endowed with a labor force composed of both high- and low-skill individuals. The latter are only qualified for low-tech jobs, while the former are qualified for both high- and low-tech jobs. ${ }^{3}$ Upon entry into a market ex ante identical firms make an irreversible investment decision to adapt one of two possible technologies: low- or high-tech production. Free entry into vacancy posting is such that both high- and low-tech firms can exist within any given country. In order to produce, firms match with workers in a labor market that is characterized by search frictions as in Diamond (1982), Mortensen (1982), and Mortensen and Pissarides (1994). Given the different employment opportunities available to high-skill workers, two types of equilibrium configurations are possible. In an ex-post segmented (EPS) equilibrium highskilled workers only accept high-tech jobs. Alternatively, under certain conditions a crossskill matching (CSM) equilibrium - that is, one in which high-skilled workers are willing to accept both high- and low-tech (mismatch) jobs - can arise.

We make two improvements relative to the original model used in DMS. First, a key limitation of the DMS setup is that there are no explicit international production linkages. Our paper improves on this by introducing a richer production structure. Specifically, we assume that in the North there exists a multinational firm that produces output using a flexibly parameterized constant elasticity of substitution (CES) aggregator of domestic and foreign (offshored) high-tech inputs. The second improvement is that our analysis is carried out in a version of the model that is carefully calibrated using data from both the U.S. and emerging market economies.

The paper has two main results. First, we show that mismatch employment helps mitigate adverse labor market consequences that arise as a result of offshoring. We show this

\footnotetext{
${ }^{3}$ This definition of skill, taken from Albrecht and Vroman (2002), is also used in Burdett and Mortensen (1998), Mortensen and Pissarides (1999), Gautier (2002), Dolado, Jansen, and Jimeno (2009), and Arseneau and Epstein (2014a).
} 
by first qualitatively reproducing the results in DMS under which a trade liberalization triggers a switch from EPS to CSM equilibrium. We then isolate the effect of mismatch by forcing the economy from a post-liberalization CSM equilibrium (with mismatch) to a postliberalization EPS equilibrium (without mismatch). The difference in allocations across the two post-liberalization outcomes reveal that by allowing domestic high-skilled labor to reallocate across both the remaining high- and low-tech industries, mismatch helps to dampen both the increase in the unemployment rate and the decline in wages that result from shifting domestic production abroad. This finding is essentially an open economy extension of Albrecht and Vroman's (2002) result on the impact of skill-biased technological change in a closed economy setting. From a policy perspective, it suggests that some degree of mismatch is actually desirable from an aggregate perspective because it helps facilitate adjustment in the labor market following a trade liberalization.

The second result is more technical in nature. We show that under our calibration the size of the parameter space over which it is possible for mismatch to emerge as an equilibrium outcome is limited. In particular, as long as the size of the high-tech offshoring sector remains relatively small — which appears to be the most empirically relevant casehighly-skilled workers will only choose to enter into mismatch employment if domestic and foreign inputs are sufficiently complementary in the multinational's production function. If the two inputs are instead viewed as substitutes, the calibrated economy lies in a part of the parameter space where mismatch does not arise in a post-liberalization equilibrium.

In terms of related literature, beyond the empirical papers cited above, there is a large body of literature, surveyed by Helpman (2006), on offshoring within the context of standard trade theory with frictionless labor markets. Grossman and Rossi-Hansberg (2008) is a relatively recent contribution. More recently, a growing number of studies have extended the offshoring literature to include equilibrium unemployment. Examples of these studies include Mitra and Ranjan (2010), Arseneau and Leduc (2012), and Ranjan (2013). In a slightly different direction, both Oldenski (2014) and Acemoglu, Gancia, and Zilibotti (2012) study the role of offshoring in the polarization of the U.S. labor force - that is, the trend decline in middle-income occupations. This paper is different from this earlier literature because - like DMS, which, in turn, builds on a long research agenda summarized in Davidson and Matusz 
(2009) - it focuses on the interaction between offshoring and mismatch unemployment.

The remainder of the paper is organized as follows. We present the model in Section 2. Section 3 discusses our calibration strategy, and the main results are presented in Section 4. Section 5 addresses the sensitivity of our results to alternative parameterizations of the multinational's production function. Finally, Section 6 offers some concluding comments.

\section{The Model}

The world economy consists of two countries that we refer to as the North and the South. Each economy is inhabited by both high- and low-skilled workers, and there is no international migration. In addition, in each economy there is a final-output producing firm that uses domestic low-tech intermediate products, only, as inputs. There is also a vertically integrated multinational headquartered in the North that produces final output as well, but using high-tech intermediate inputs, only. In turn, intermediate inputs are produced using labor. Following related literature, we abstract from capital and assume that each intermediate goods producer has only one job.

We follow DMS regarding production configurations under autarky and trade. In autarky high-tech intermediate production occurs exclusively in the North. Under trade, offshoring takes place and high-tech intermediate goods are also produced in the South and sold to the North for use as inputs in the multinational's production of final output. Each country's final output is non-tradable. Thus, trade occurs only in intermediate goods.

Each economy's labor market is characterized by search frictions. In line with Albrecht and Vroman (2002) and DMS, search is assumed to be undirected and we abstract from onthe-job search. Undirected search simply means that per-period matches between firms and job seekers are the result of an aggregate matching technology that is increasing in aggregate vacancies and aggregate unemployment. ${ }^{4}$

\footnotetext{
${ }^{4}$ This can also be interpreted as random search, since the assumption of an aggregate meeting function is such that individuals searching for employment may encounter job opportunities that they are unwilling or unqualified to take. Alternatively, in the present context directed search would involve sectoral highand low-tech meeting functions that take as inputs sector-specific vacancies and searchers instead of their aggregate counterparts. The existence of such sectoral meeting functions imply that workers are indeed able to only search for jobs that they are qualified for and are actually willing to take. See Epstein (2012) and Arseneau and Epstein (2014a) for more on this topic.
} 
The labor market is structured such that low-skill workers in either economy are only qualified for employment in jobs operated by the corresponding domestic low-tech intermediate producers. In contrast, high-skilled workers are in principle able to attain employment in either the high-tech multinational - via high-skilled workers in the North employed by hightech intermediate producers and high-skilled workers in the South employed by offshore (high-tech) intermediate producers - or a domestic low-tech intermediate producer.

Our assumptions regarding the skill content of jobs potentially gives rise to multiple equilibria. Borrowing terminology from Albrecht and Vroman (2002), a cross skill matching equilibrium (CSM) arises when a high-skilled worker is willing to accept a job paying a lower wage in the low-tech sector in the interest of more quickly moving out of the state of unemployment. Throughout the remainder of this paper, we refer to this type of labor market outcome in CSM equilibrium as mismatch employment. In contrast, an ex-post segmentation equilibrium (EPS) arises when high-skilled workers are unwilling to accept low-tech jobs and hence only work in high-tech jobs so that mismatch employment does not arise. The conditions under which each of the noted matches can arise are discussed in Section 2.3 following development of the model.

Of note, CSM and EPS equilibria are not mutually exclusive: Under certain parameter configurations both equilibriums can exist simultaneously. For the Southern economy, in absence of offshoring CSM equilibrium obtains trivially because low-tech jobs are the only source of employment. Beyond that special case, as in Albrecht and Vroman (2002) and DMS we abstract from formal modeling mechanisms that may lead to equilibrium selection.

\subsection{The Northern Economy}

The Northern economy is inhabited by a population of infinitely lived individuals with unit mass, all of whom always participate in the labor market. A fraction $\psi \in(0,1)$ of the Northern labor force consists of low-skilled workers $(L)$. The remaining $1-\psi$ fraction of the labor force consists of high-skilled workers $(H)$.

The price of final output is normalized to unity. Both final and intermediate producers are price takers in the product market. Final goods producers are also price takers in the inputs market. However, hiring of labor at the intermediate production stage is subject to search 
frictions implying bargaining power for both workers and intermediate producers. Given this bargaining power, following related search literature we assume that wages are negotiated via Nash bargaining with no commitment to the future path of wages (that is, wages can be instantaneously renegotiated given changes in the economic environment). High- and low-tech intermediate producers fill open positions through vacancy posting. Free entry into vacancy posting is such that both high- and low-tech intermediate producers coexist.

\subsubsection{Production}

Final output produced using low-tech $(L)$ intermediate inputs is given by $Y_{L}=Z_{L} N_{L}$, where: $Z_{L}$ is technology; and $N_{L}$ is the total amount of low-tech intermediate inputs. As noted earlier, we assume that all product markets - both final goods and intermediate goods - are perfectly competitive and that final goods producers are price takers in the input market. Letting $p_{L}$ denote the price of low-tech intermediate input, the profit-maximization problem of final goods production using low-tech intermediate inputs is

$$
\max _{N_{L}} Z_{L} N_{L}-p_{L} N_{L}
$$

Thus, in equilibrium

$$
p_{L}=Z_{L}
$$

Since each intermediate producer has only one job, then $N_{L}=z_{L} \varepsilon_{L}+z_{M} e_{M}$, where: $z_{L}$ is the productivity of a match between a low-skill worker and a low-tech intermediate producer; $\varepsilon_{L}$ is the mass of low-skilled individuals working for intermediate low-tech producers; $z_{M}$ is the productivity of a mismatch employment relationship; and $e_{M}$ is the mass of mismatch (high-skilled) individuals working for intermediate low-tech producers (in CSM equilibrium $e_{M}>0$ and in EPS equilibrium $e_{M}=0$ ). Alternatively, $\varepsilon_{L}+e_{M}$ is also the mass of lowtech intermediate producers that are operating at any given point in time. It follows that $y_{L}=p_{L} z_{L}$, where $y_{L}$ is the value of output for a low-tech intermediate producer matched with a low-skill individual, and $y_{M}=p_{L} z_{M}$ is the value of mismatch output.

The multinational produces final goods $Y_{H}$, and can do so using domestic intermediate high-tech $(H)$ inputs and high-tech inputs produced in the South via offshoring $(O)$. We 
assume the constant elasticity of substitution (CES) function

$$
Y_{H}=Z_{H}\left[\eta\left(N_{H}\right)^{\sigma}+(1-\eta)\left(N_{O}\right)^{\sigma}\right]^{1 / \sigma}
$$

where: $Z_{H}$ is technology; $N_{H}$ is total amount of domestic high-tech intermediate inputs; $N_{O}$ is total amount of offshore (high-tech) intermediate inputs; and the parameters $\eta$ and $\sigma$ are, respectively, the share of domestic intermediate high-tech inputs and the degree of substitutability between domestic and offshore intermediate high-tech inputs. ${ }^{5}$ In the absence of trade, $\eta=1$. Note that the multinational production function establishes explicit international linkages between countries, which is an innovation of our modeling approach relative to DMS, where no explicit international linkages were considered.

The profit-maximization problem of the multinational is

$$
\max _{N_{H}, N_{O}} Z_{H}\left[\eta\left(N_{H}\right)^{\sigma}+(1-\eta)\left(N_{O}\right)^{\sigma}\right]^{1 / \sigma}-p_{H} N_{H}-p_{O} N_{O}
$$

where: $p_{H}$ is the price of high-tech Northern intermediate inputs; and $p_{O}$ is the price of offshore inputs. The first-order conditions imply that

$$
p_{H}=Z_{H} \eta\left(N_{H}\right)^{\sigma-1}\left[\eta\left(N_{H}\right)^{\sigma}+(1-\eta)\left(N_{O}\right)^{\sigma}\right]^{1 / \sigma-1}
$$

and

$$
p_{O}=Z_{H}(1-\eta)\left(N_{O}\right)^{\sigma-1}\left[\eta\left(N_{H}\right)^{\sigma}+(1-\eta)\left(N_{O}\right)^{\sigma}\right]^{1 / \sigma-1}
$$

$N_{H}=z_{H} \varepsilon_{H}$ and $N_{O}=z_{O} \varepsilon_{O}$, with analogous interpretation as earlier. In particular, $\varepsilon_{H}$ is the mass of Northern high-skilled workers employed by Northern high-tech intermediate producers and $\varepsilon_{O}$ is the mass of Southern high-skilled individuals employed by offshore intermediate producers. It follows that for $i \in\{H, O\} y_{i}=p_{i} z_{i}$, where $y_{i}$ is the value of output for a type- $i$ intermediate producer.

\footnotetext{
${ }^{5} \sigma=1$ implies perfect substitutability, $\sigma=-\infty$ implies perfect complementarity, and $\sigma=0$ is the Cobb-Douglas production-function case.
} 


\subsubsection{Matching Process}

Let $m$ denote matches per period. In line with related literature, $m$ is assumed to be increasing and concave in aggregate vacancies $v$ and aggregate unemployment $u$. Aggregate vacancies are equal to the sum of low- and high-tech vacancies posted by intermediate producers, respectively $v_{L}$ and $v_{H}$. Similarly, aggregate unemployment is equal to the sum of the masses of low- and high-skill unemployed individuals, respectively $u_{L}$ and $u_{H}$. Note that because the population consists of a unit mass and all individuals participate in the labor force, then $u$ is also the aggregate unemployment rate.

$\gamma_{L} \in(0,1)$ is the fraction of unemployed low-skilled individuals relative to total unemployment, that is, $\gamma_{L}=u_{L} / u$. In addition, $q=m / v$ is meetings per vacancy, that is, the rate at which intermediate producers with open positions meet workers. It follows that $q \gamma_{H}$, where $\gamma_{H}=1-\gamma_{L}$, is the rate at which any intermediate producer with a vacancy meets a low-skill unemployed worker, and $q \gamma_{H}$ is the rate at which any intermediate producer with a vacancy meets a high-skill unemployed worker. Note that all meetings between workers and firms do not result in a match. Indeed, when a low-skill worker and a high-tech intermediate producer meet, no match is formed, which is also the case when a high-skill worker and a low-tech intermediate producer meet in EPS equilibrium.

Let $\phi_{L}$ denote the fraction of low-tech vacancies relative to aggregate vacancies, that is, $\phi=v_{L} / v$. In addition, $f=m / u$ is the rate at which unemployed individuals of any type meet intermediate producers with vacancies of any given type. Thus, an unemployed individual meets a firm with a low-tech vacancy at effective rate $f \phi_{L}$ and a firm with a high-tech vacancy at effective rate $f \phi_{H}$, where $\phi_{H}=1-\phi_{L}$.

\subsubsection{Value Functions}

Intermediate Producers For $i, j \in\{L, H\}$ and $i=j$ the value to a Northern intermediate producer of type $i$ from employing a type- $j$ worker $J_{i}$ satisfies

$$
r J_{i}=y_{i}-c-w_{i}-\delta\left(J_{i}-V_{j}\right)
$$


where: $r$ is the interest rate in the Northern economy; $c$ is the Northern fixed flow cost of posting a vacancy and maintaining a job; $y_{j}$ is the value of output of a match as defined earlier; $w_{i}$ is the Nash bargained wage; $\delta$ is the exogenous economy-wide rate of job destruction in the North; and $V_{i}$ is the value of an unfilled vacancy posted by a Northern type- $i$ intermediate producer. The value of mismatch employment for a low-tech firm $J_{M}$ is the same as the expression above but with $i=M$ and $j=L$. Intuitively, the firm's value from a filled position is equal to a worker's marginal value of production in that job net of the wage, the job-maintenance cost, and the expected capital loss owing to job destruction.

Given the meeting process described above, for $i \in\{L, H\}$ the value of a vacancy for a type- $i$ firm $V_{i}$ satisfies

$$
r V_{i}=-c+q \gamma_{i}\left(J_{i}-V_{i}\right)+\mathbb{I}_{L} q \gamma_{H}\left(J_{M}-V_{L}\right)
$$

where: $\mathbb{I}_{L}$ is an indicator function whose value is equal to 1 with $i=L$ in CSM equilibrium, while it takes a value of zero in the event that $i=H$ or in EPS equilibrium if $i=L$.

Workers For $i, j \in\{L, H\}$ and $i=j$ the value to a Northern worker of type $i$ from being employed by a type- $j$ firm $W_{i}$ satisfies

$$
r W_{j}=w_{j}-\delta\left(W_{j}-U_{i}\right)
$$

This equation says that the corresponding employment flow value to a worker is equal to the wage paid in the position net of the expected capital loss owing to job destruction. The value of mismatch employment for a high-skill worker $W_{M}$ is the same as the expression above but with $j=M$ and $i=H$.

For $i \in\{L, H\}$ the value of unemployment for a Northern type- $i$ worker $U_{i}$ satisfies

$$
r U_{i}=b+f \phi_{i}\left(W_{i}-U_{i}\right)+\mathbb{I}_{H} f \phi_{L}\left(W_{M}-U_{H}\right),
$$

where: $\mathbb{I}_{H}$ is an indicator function whose value is equal to 1 with $i=H$ in CSM equilibrium, while it takes a value of zero if $i=L$ or in EPS equilibrium if $i=H$. It follows that 
unemployment flow values are equal to the sum of unemployment flow benefits and the expected capital gains from becoming employed.

\subsubsection{Surpluses}

The surplus of a match is equal to the sum of the capital gains that firms and workers obtain from forming an employment relationship. Thus, for $i, j, k \in\{L, H\}$ and $i=j=k$ match surpluses from high-skill workers matched with high-tech jobs and low-skill workers matched with low-tech jobs are given by

$$
S_{j}=J_{j}-V_{i}+W_{j}-U_{k}
$$

With $j=M, i=L$ and $k=H$ the preceding equation also defines the surplus from mismatch. In all cases, if the value of a particular job is positive for a firm, then free entry into vacancy posting implies $V_{i}=0$, which is what implicitly allows for the existence of both high- and low-tech intermediate goods producers within any given country.

\subsubsection{Wages}

Let $\beta \in(0,1)$ denote workers' exogenously determined constant bargaining power. Nash bargaining of wages without commitment to the future path of wages (that is, wages can be instantaneously renegotiated given changes in the economic environment) implies a surplus sharing rule by which a worker's capital gain from becoming employed is a constant fraction $\beta$ of the associated surplus, and similarly a firm's capital gain derived from forming an employment relationship is a constant fraction $1-\beta$ of the associated surplus. Thus, Nash bargaining implies that for $i, j, k \in\{L, H\}$ and $i=j=k$ the wage $w_{i}$ is implicitly defined by

$$
\left(W_{j}-U_{k}\right)=\frac{\beta}{1-\beta}\left(J_{j}-V_{i}\right)
$$

In turn, the mismatch wage satisfies the equation above with $j=M, k=H$, and $i=L$.

Also, note that the average wage of low-skill workers $\bar{w}_{L}$ is simply equal to $w_{L}$, while the 
average wage of high-skill workers $\bar{w}_{H}$, is

$$
\bar{w}_{H}=\frac{\varepsilon_{H} w_{H}+e_{M} w_{M}}{1-\psi-u_{H}},
$$

Finally, the Northern aggregate wage $\mathbb{W}$ is given by

$$
\mathbb{W}=\frac{\varepsilon_{L} w_{L}+\varepsilon_{H} w_{H}+e_{M} w_{M}}{1-u} .
$$

\subsubsection{Flow Equilibrium Conditions}

Three equilibrium flow conditions must be accounted for, defining: 1) the mass of unemployed low-skilled individuals; 2) the mass of unemployed high-skill individuals; and 3) the mass of mismatched individuals. Since all employment relationships end at exogenous rate $\delta$ and low-skill individuals exit unemployment at effective rate $f \phi_{L}$, it follows that in equilibrium the mass of low-skill unemployed individuals satisfies

$$
\delta\left(\psi-\gamma_{L} u\right)=f \phi_{L} \gamma_{L} u
$$

Using similar reasoning, the equilibrium mass of unemployed high-skilled individuals satisfies

$$
\delta\left(1-\psi-\gamma_{H} u\right)=f\left(\phi_{H}+\mathbb{I}_{H} \phi_{L}\right) \gamma_{H} u
$$

Furthermore, high-skill workers become mismatch employed at effective rate $\mathbb{I}_{H} f \phi_{L}$. therefore, the equilibrium mass of high-skilled workers employed by low-tech firms satisfies

$$
\mathbb{I}_{H} f \phi: \gamma_{H} u=\delta e_{M}
$$

Of course, the total number of individuals employed by high-tech firms is

$$
\varepsilon_{H}=1-\psi-\gamma_{H} u-e_{M},
$$


and the total number of low-skilled individuals employed by low-tech firms is

$$
\varepsilon_{L}=\psi-\gamma_{L} u
$$

Note that the unemployment rate of low-skill workers is $u_{L} / \psi$, and similarly that of highskill workers is $u_{H} /(1-\psi)$. Moreover, the rate of mismatch employment to total high-skill employment is $e_{M} /\left(1-\psi-u_{H}\right)$.

\subsection{The Southern Economy}

Recall that, following DMS, we assume that while the Southern labor force consists of both high- and low-skill individuals, under autarky in the South only low-tech intermediate producers exist whose input is used in the final production of Southern goods. In turn, offshoring of intermediate high-tech production for use as input in the multinational's production of final output in the North introduces a high-tech (offshoring) sector in the South.

Akin to the Northern economy, in the South low-skill workers are only productive in low-tech intermediate firms, while high-skill workers can produce in both low- and hightech (offshore) intermediate firms. Under autarky the Southern economy is trivially in CSM equilibrium and the Southern ratio of mismatch to total high-skill employment is equal to 1 (given no other employment alternative Southern high-skill workers find it optimal to take low-tech jobs).

For expositional brevity we omit full development of the Southern economy. All notation and assumptions about the Southern economy are analogous to those noted earlier in the development of the Northern economy under the appropriate configurations except for the following. First, variables and parameters corresponding explicitly to the South are distinguished by use of an asterisk. Second, high-tech offshore variables and parameters are denoted with an $O$ (instead of an $H$ ). Third, in an equilibrium with trade the value of a job

to an offshore intermediate high-tech producer - that is, the value to a high-tech intermediate firm located in the South that employs a Southern high-tech worker and sells its production 
to the Northern multinational $-J_{O}^{*}$ satisfies

$$
r^{*} J_{O}^{*}=y_{O}-c^{*}-c_{O}^{*}-w_{O}^{*}-\delta^{*}\left(J_{O}^{*}-V_{O}^{*}\right),
$$

where: $c_{O}^{*}$ is a fixed flow cost specifically associated with maintaining an offshore job and posting offshore vacancies. It follows that the value of an offshore vacancy $V_{O}^{*}$ satisfies

$$
r^{*} V_{O}^{*}=-c^{*}-c_{O}^{*}+q^{*} \gamma_{H}^{*}\left(J_{O}^{*}-V_{O}^{*}\right)
$$

(note that in an equilibrium with trade total vacancies in the South $v^{*}$ are equal to the sum of Southern low-tech vacancies $v_{L}^{*}$ and offshore vacancies $v_{O}^{*}$; in addition, the fraction of low-tech vacancies is $\phi_{L}^{*}$, and the fraction of offshore vacancies is $\left.\phi_{O}^{*}=1-\phi_{L}^{*}\right)$. Fourth, in similar spirit to DMS, we assume that autarky is consistent with the value of $c_{O}^{*}$ being prohibitively high. However, a decline in $c_{O}^{*}$ to a sufficiently small value is consistent with the world economy moving to an equilibrium with trade (for simplicity, we assume that trade is associated with the value of $c_{O}^{*}$ having effectively dropped to zero, therefore inducing entry into the offshore market).

\subsection{Equilibrium}

Following DMS, our baseline world equilibrium assumptions are that: 1) under autarky the North is in EPS equilibrium (while the South is trivially in CSM equilibrium); 2) under trade high-skilled workers in the North become sufficiently pessimistic about their future job market prospects triggering a switch to CSM equilibrium; 3) for simplicity, under trade the wages associated with offshore employment are perceived by Southern high-skill workers as being sufficiently high that they stop accepting low-tech jobs, triggering a switch to EPS equilibrium. Unlike DMS, we later assess the impact of mismatch in the North by considering an alternative trade equilibrium in which both the North and the South are in EPS equilibrium. Moreover, we discuss why in autarky a CSM equilibrium in the North would not emerge under our baseline calibration.

For expositional brevity, in the remainder of this section whenever possible we focus the 
discussion on the Northern economy. Analogous considerations to those presented, when applicable, are straightforward for the South.

In line with related literature, we assume free entry into vacancy posting. This assumption implies that the value of a vacancy for any intermediate producer is equal to zero.

\subsubsection{Preliminaries}

Key Equilibrium Variables Recall from earlier that the matching function $m$ was assumed to be increasing and concave in aggregate vacancies and aggregate unemployment. Following related literature we assume that $m=A v^{\alpha} u^{1-\alpha}$, where $A$ is matching efficiency and $\alpha \in(0,1)$ is the elasticity of matches with respect to aggregate vacancies. Let $\theta=v / u$ denote market tightness. It follows that the rate at which workers meet firms can be stated as $f=A \theta^{\alpha}$, which is increasing in market tightness, and the rate at which firms meet workers is $q=A \theta^{\alpha-1}$, which is decreasing in market tightness. The preceding, along with the surplus definitions and Nash bargaining surplus-sharing rules, implies that key equilibrium conditions can be stated in terms of market tightness (rather than aggregate vacancies and aggregate unemployment) and also in terms of surpluses (rather than agent-specific value functions).

Existence For EPS equilibrium to exist, it must be the case that the surplus from a match between a low-skilled worker and a low-tech intermediate firm is positive and that the surplus from a match between a high-skill worker and a high-tech intermediate firm is positive as well. Solving explicitly for surpluses in EPS equilibrium (which is straightforward given the definition of surplus from earlier as well as relevant value function statements) it follows that $y_{L}>c+b$ and $y_{H}>c+b$ are necessary and sufficient conditions for, respectively, $S_{L}>0$ and $S_{H}>0$ to hold.

For CSM equilibrium to be viable it must be the case that: $S_{L}>0 ; S_{H} \geq 0$; and the surplus from a match between a high-skilled worker and a low-tech intermediate firm (mismatch) is positive: $S_{M}>0$ (again, solving for $S_{H}, S_{M}$, and $S_{L}$ in CSM equilibrium is straightforward given their definitions and relevant value function statements; in the event that $S_{H}=0$ high-tech firms do not post vacancies meaning that with all individuals par- 
ticipating in the labor force $S_{L}>0$ and $S_{M}>0$ are such that CSM equilibrium emerges trivially). Suppose this is the case. Then, subtracting the surplus $S_{H}$ from the surplus $S_{M}$ and rearranging implies that

$$
S_{H}-S_{M}=\frac{y_{H}-y_{M}}{r+\delta} .
$$

That is, the difference between the surplus from a match between a high-skilled worker and a high-tech firm and the surplus from mismatch is simply equal to a weighted difference of the value of output between these matches. Now, rearranging the surplus $S_{M}$ and substituting in equation (9) yields

$$
(r+\delta+f \beta) S_{M}=y_{M}-(c+b)-\frac{f \phi_{H} \beta}{r+\delta}\left(y_{H}-y_{M}\right) .
$$

Therefore, $S_{M}$ is positive if and only if

$$
y_{M}-(c+b)>\frac{f \phi_{H} \beta}{r+\delta}\left(y_{H}-y_{M}\right) .
$$

It follows from equation (9) that if $y_{H}>y_{M}$ it is necessarily the case that $S_{H}>S_{M}$ (and $S_{H}>0$ if $S_{M}>0$ ). Furthermore, inequality (10) is satisfied (and hence $S_{M}>0$ ) if the difference between the output value of mismatch and the sum of unemployment flow benefits and the cost of of maintaining a job is larger than a weighted difference between the value of high-tech and mismatch intermediate output.

Note that, all else equal, the smaller the difference between $y_{M}$ and $y_{H}$ is, as well as the smaller $\phi_{H}$ is, the more likely it is that inequality (10) is indeed satisfied. Intuitively, as $\phi_{H} \rightarrow 0$ high-tech jobs become increasingly scarce, and in the limit they are entirely unavailable meaning that high-skill workers' outside (high-tech) employment options do not weigh on mismatch surplus. An analogous interpretation follows from considering the case in which $y_{M} \rightarrow y_{H}$.

As noted earlier, EPS and CSM equilibrium configurations are not mutually exclusive. Indeed, as long as $y_{L}>c+b$ and $y_{H}>c+b$, then EPS equilibrium always exists. Should the preceding hold and the economy's parameters be such that CSM equilibrium also exists, then as noted in DMS whether the economy settles on EPS or CSM equilibrium can depend 
on many factors, including, for instance, high-skill workers' expectations about high-tech employment prospects.

Vacancy Creation Conditions Rearrangement of the Northern vacancy flow value equations along with free-entry into vacancy-posting and the definition of surplus and Nash bargaining imply for $i \in\{L, H\}$ the following Northern vacancy-creation condition:

$$
(1-\beta)\left(\gamma_{i} S_{i}+\mathbb{I}_{L} \gamma_{H} S_{M}\right)=c / q
$$

These equations hold when the value of a particular type of job to a firm is positive, and simply say that given free-entry into vacancy creation the expected gains from posting lowor high-tech vacancies (the left-hand side) are equal to the expected costs (the right-hand side). In the South, similar reasoning applies leading for $i \in\{L, O\}$ to the following Southern vacancy-creation condition:

$$
\left(1-\beta^{*}\right)\left(\gamma_{i}^{*} S_{i}^{*}+\left(1-\mathbb{I}_{O}^{*}\right) \gamma_{H}^{*} S_{M}^{*}\right)=c^{*} / q^{*}
$$

where: $\mathbb{I}_{O}^{*}$ is an indicator function equal to 0 if $i=L$ and the Southern economy is in autarky and equal to 1 if offshoring occurs and $i=O$ or $i=L$.

\subsubsection{Definitions}

Given the development thus far, in all definitions that follow knowledge of the fundamental vectors $\mathbb{S}$ and $\mathbb{V}$ is sufficient to solve for any other endogenous variables and equilibrium flow equations of interest.

Definition 1: autarky equilibrium with North in EPS configuration and South in CSM configuration. A steady-state autarky equilibrium with ex-post segmentation in the North and (trivial) cross-skill matching in the South consists of a set of value functions $\mathbb{S}=\left\{S_{L}\right.$, $\left.S_{H}, S_{L}^{*}, S_{M}^{*}\right\}$ and a vector $\mathbb{V}=\left\{\theta, \phi_{L}, \gamma_{L}, u, \theta^{*}, \gamma_{L}^{*}, u^{*}, e_{M}^{*}, p_{H}, p_{L}, p_{L}^{*}\right\}$ such that:

1. The following are solved: the two corresponding Northern surplus equations implied by equation (5) and the two analogous surplus equations for the South, the two corresponding Northern vacancy-creation condition equations implied by equation (11), 
the single corresponding vacancy-creation condition for the South implied by equation (12), the two Northern price equations (1) and (3) with $\eta=1$ and the single analogous (low-tech) price equation for the South, equations (6), (7) and the two analogous unemployment equations for the South, and also the single Southern equation defining mismatch employment analogous to its Northern counterpart (equation (8)).

2. $S_{L}>0, S_{H}>0, S_{L}^{*}>0, S_{M}^{*}>0$.

Definition 2: trade equilibrium with both the North and South in EPS configurations. A steady-state trade equilibrium with ex-post segmentation in both the North and South consists of a set of value functions $\mathbb{S}=\left\{S_{L}, S_{H}, S_{L}^{*}, S_{O}^{*}\right\}$ and a vector $\mathbb{V}=\left\{\theta, \phi_{L}, \gamma_{L}, u\right.$, $\left.\theta^{*}, \phi_{L}^{*}, \gamma_{L}^{*}, u^{*}, p_{H}, p_{L}, p_{L}^{*}, p_{O}\right\}$ such that:

1. The following are solved: the two corresponding Northern surplus equations implied by equation (5) and the two analogous surplus equations for the South, the two corresponding Northern vacancy-creation condition equations implied by equation (11), the two corresponding vacancy-creation conditions for the South implied by equation (12), the three Northern price equations (1), (3), (4) (with $\eta=0$ ) and the single analogous (low-tech) price equation for the South, equations (6), (7) and the two analogous unemployment equations for the South.

2. $S_{L}>, S_{H}>0, S_{L}^{*}>0, S_{O}^{*}>0$.

Definition 3: trade equilibrium with the North in CSM configuration and the South in EPS configuration. A steady-state trade equilibrium with cross-skill matching in the North and ex-post segmentation in the South consists of a set of value functions $\mathbb{S}=\left\{S_{L}, S_{H}, S_{M}\right.$, $\left.S_{L}^{*}, S_{O}^{*}\right\}$ and a vector $\mathbb{V}=\left\{\theta, \phi_{L}, \gamma_{L}, u, e_{M}, \theta^{*}, \phi_{L}^{*}, \gamma_{L}^{*}, u^{*}, p_{H}, p_{L}, p_{L}^{*}, p_{O}\right\}$ such that:

1. The following are solved: the three corresponding Northern surplus equations implied by equation (5) and the two analogous surplus equations for the South, the two corresponding Northern vacancy-creation condition equations implied by equation (11), the two corresponding vacancy-creation conditions for the South implied by equation (12), the three Northern price equations (1), (3), (4) (with $\eta=0$ ) and the single analogous 
(low-tech) price equation for the South, equations (6), (7), (8) and the two analogous unemployment equations for the South.

2. $S_{L}>0, S_{H} \geq 0, S_{M}>0, S_{L}^{*}>0, S_{O}^{*}>0$.

In light of the preceding definitions, the definition of an autarky equilibrium with both the North and South in CSM configurations is straightforward.

\section{Calibration}

The baseline calibration is summarized in Table 1 and assumes a trade equilibrium with the North in CSM configuration and the South in EPS configuration (this is consistent with equilibrium Definition 3 above). The frequency is monthly, so the interest rates are set to $r=r^{*}=0.004$, which is consistent with an annual interest rate of 5 percent.

\subsection{Northern Economy}

As in Arseneau and Epstein (2014a), we assume that individuals with at least some postsecondary education are high-skill workers while those with at most a high school degree correspond to low-skill workers. Bureau of Labor Statistics (BLS) data shows that about half of the U.S. population has at most a high school degree. Therefore, we set the fraction of low-skilled individuals in the Northern economy to $\psi=0.5$.

As noted earlier, the job market is characterized by a standard Cobb-Douglas matching function. We set the elasticity of the matching function with respect to aggregate vacancies $\alpha$ to 0.5 , which is broadly in line with research surveyed in Petrongolo and Pissarides (2001). The matching efficiency parameter $A$ is calibrated as follows. Using aggregate monthly data on unemployment since 1951 that is available publicly from the BLS along with the methodology in Elsby, Michaels, and Solon (2009) and Shimer (2012), we find that in the U.S. the probability that an average unemployed individual finds a job within a month is 0.43. Given this figure, assuming an underlying Poisson distribution implies that the rate at which an average unemployed individual finds a job is 0.56. Therefore, the matching

efficiency parameter is used to attain the steady state value of $\frac{f \phi_{H} u_{H}+f \phi_{L} u_{L}}{u}=0.56$. 
The exogenous job destruction probability $\delta$ is calibrated using data on aggregate unemployment from the BLS. These data show that since 1951 the average US unemployment rate is 0.058 . Therefore, we pin down the job destruction rate by targeting the steady-state value $u=0.058$. In turn, the cost of posting vacancies $c$ is used to target the ratio of aggregate vacancies to aggregate unemployment: $v / u=0.68$. This figure is obtained using data on aggregate job openings from the BLS Job Openings and Labor Turnover Survey since 2000 (when first available) along with the Conference Board's Help-Wanted Index from 1951 through 2000. Combined with the BLS time series for aggregate unemployment, these data imply that in the U.S. the average ratio of aggregate vacancies to aggregate unemployment is 0.68 in the post-war period.

We assume symmetry in bargaining power, so that $\beta=0.5$. This parameterization has the virtue that, in our model, $\beta=\alpha$ delivers an efficient split of match surplus (see Hosios (1990)). Broadly in line with Shimer (2005), unemployment benefits $b$ are set to deliver a 40 percent replacement rate of aggregate wages. In particular, we set $b=0.4 \frac{w_{H} \varepsilon_{H}+w_{L} \varepsilon_{L}}{1-u}$.

For production, we normalize the intermediate input technology parameters so that $z_{H}=$ $z_{L}=z_{O}=1$. In addition, we follow DMS and assume that the technology parameter in the final low-tech goods aggregator is $Z_{L}=1.6$ and that the value of intermediate hightech production in the North is 12.5 percent higher than its low-tech counterpart. This last assumption pins down the technology parameter of the final-high tech goods aggregator $Z_{H}$ and results in a wage premium of correctly match high-skill workers relative to correctly matched low-skill workers of nearly 20 percent. In addition, we set the share of domestic intermediate inputs in the multinational's production function to $\eta=0.9$, broadly in line with Burstein, Kurtz, and Tesar (2008), though lower than used in Arseneau and Leduc (2012). We discuss the choice of the multinational's substitutability parameter $\sigma$ in the following section, as it is relevant for wage differentials in the South.

Finally, the analysis in Sicherman (1991) suggests that each year of overeducation relative to a job's educational requirements induces an overeducation wage premium of nearly 4 percent relative to individuals with the required amount of education. Given that our reference for the model's high-skill workers are individuals with at least some post-secondary education - which can include attaining a college degree and higher - we use the mismatch 
productivity parameter $z_{M}$ to target a conservative wage ratio of $w_{M} / w_{L}=1.135$.

\subsection{Southern Economy}

Our Southern country is meant to be a representative emerging market economy. In particular, we have in mind countries classified as emerging economies by the International Monetary Fund, including Argentina, Brazil, Bulgaria, Chile, China, Colombia, Hungary, India, Indonesia, Latvia, Lithuania, Malaysia, Mexico, Pakistan, Peru, Philippines, Poland, Romania, Russia, South Africa, Thailand, Turkey, Ukraine, and Venezuela. Publicly available data from the World Bank shows that across our list of emerging economies the average fraction of the population that completed at most a secondary education is about 0.8 . Therefore, we set the fraction of low-skilled individuals in the Southern economy to $\psi^{*}=0.8$.

As in the North, the Southern job market is characterized by a standard Cobb-Douglas matching function. In line with Petrongolo and Pissarides (2001) we set $\alpha^{*}=0.5$. Data on worker flows is quite limited for emerging economies. Therefore, we calibrate the matching efficiency parameter $A^{*}$ following Bosch Mossi and Maloney (2007), who calculate transition rates for Mexico at quarterly frequency. We assume an underlying Poisson distribution and use Bosch and Maloney's findings to back out a representative implied monthly job finding rate for Mexico of 0.11 . Thus, akin to the Northern economy we choose $A^{*}$ so that $\frac{f^{*} \phi_{L}^{*} u_{L}^{*}+f^{*} \phi_{O}^{*} u_{H}^{*}}{u^{*}}=0.11$

The exogenous job destruction probability $\delta^{*}$ is calibrated using data on aggregate unemployment rates from statistical agencies of nearly all our reference emerging economies. Taken at face value, these data suggest an average unemployment rate across emerging economies of about 10 percent. Therefore, we pin down the job destruction rate by targeting the steady-state value $u^{*}=0.1$. In turn, the cost of posting vacancies $c^{*}$ is used to target the ratio of aggregate vacancies to aggregate unemployment: $v^{*} / u^{*}=0.2$. We obtain this figure by taking at face value data on aggregate job openings from several emerging market statistical agencies. ${ }^{6}$ In addition, recall that under trade we assume that the offshore-specific flow cost is $c_{O}^{*}=0$.

As in the Northern economy, we assume symmetry in bargaining power so that $\beta^{*}=0.5$.

\footnotetext{
${ }^{6}$ In particular, Bulgaria, Lithuania, Malaysia, Philippines, Poland, and Chile.
} 
Many emerging market economies have no formal unemployment insurance scheme, which would argue for setting $b^{*}=0$. Nevertheless, we take the midpoint between that lower bound and the replacement rate in the North and choose instead to set $b^{*}=0.2 \frac{w_{M}^{*} e_{M}^{*}+w_{L}^{*} \varepsilon_{L}^{*}}{1-u^{*}}$.

Turning towards production, we normalize $z_{L}^{*}=1$. In addition, we follow DMS and assume that the value of Southern low-tech intermediate production is about 40 percent of that of Northern high-tech intermediate production, which pins downs the technology parameter $Z_{L}^{*}$.

Finally, we pin down the multinational's substitutability parameter $\sigma$ by assuming a wage ratio $w_{O}^{*} / w_{L}^{*}=1.3$. This wage ratio is higher than its counterpart in the North in the spirit of the assumption that Southern high-tech workers find offshore wages sufficiently high that EPS configuration emerges under trade. As noted in Table 1, the resulting value of $\sigma$ implies strong complementarity (the baseline calibration is such that for any target $w_{O}^{*} / w_{L}^{*}>1$ a negative value for $\sigma$ always emerges).

\section{Quantitative Results}

As noted earlier, our baseline exercise involves assessing the impact of a trade liberalization by comparing the benchmark trade equilibrium to an autarky equilibrium in which the North is in EPS configuration and the South is trivially in CSM configuration. When implementing the trade liberalization, we assume that all country-specific parameters remain as in the benchmark trade equilibrium. In addition, when the South moves to a post-liberalization CSM equilibrium we assume a mismatch wage premium of 13.5 percent (as was the case for the North in CSM equilibrium). This assumption pins down a value for the Southern mismatch productivity parameter $z_{M}^{*}=1.03$.

We choose to compare the benchmark trade equilibrium to an autarky EPS equilibrium in

the North for two reasons. First, doing so allows our results to be more directly comparable to those reported previously in DMS, who, as noted earlier, analyze a trade liberalization under the assumption that high-skilled workers in the Northern economy become sufficiently pessimistic about their future job market prospects such that it induces a shift from EPS to CSM equilibrium. Second - and most importantly - an autarky equilibrium in which the 
North is in CSM does not exist under our baseline parameterization. This is because our calibration, which is informed by observable data on both U.S. and emerging economy labor markets, implies that under autarky the value of Northern intermediate high-tech production is so much higher than the value of Northern intermediate low-tech production that the mismatch surplus is driven below zero. Hence, mismatch is not supported in the autarky equilibrium under the baseline calibration.

\subsection{Main Results}

The baseline results are presented in Table 2. The switch from autarky (Case A) to offshoring under the assumption that the North moves to a post-liberalization CSM equilibrium (Case B) results in a decline in both the aggregate Northern unemployment rate, $u$, and aggregate Northern wage, $\mathbb{W}$. Thus, from the perspective of the Northern economy, the increase in offshoring carries both a benefit and a cost from the perspective of the aggregate labor market - the trade liberalization increases the number of people working, but the aggregate wage declines.

Disaggregating to the sectoral level, an immediate consequence of offshoring is that the multinational shifts high-tech production away from the Northern economy toward the Southern economy. As a result, high-tech vacancies fall in the North and rise in the South. The resulting reduction in demand for Northern high-skilled labor lowers wages in the hightech sector. Faced with declining wages and fewer job openings, high-skilled individuals become willing to accept lower quality jobs in the low-tech sector, inducing a switch to CSM equilibrium. Indeed, note that the Northern mismatch rate, $e_{U} /\left(1-\psi-u_{H}\right)$, rises from 0 to 0.63 . In spite of lower vacancies in the high-tech sector, new job opportunities that arise from the willingness of high-skilled individuals to accept employment in the low-tech industry help to push down the high-skilled unemployment rate, $u_{H} /(1-\psi)$ by nearly 1.5 percentage points.

From the perspective of job creation in the low-tech sector, mismatch generates two opposing effects. On the one hand, because Northern low-tech firms now expect to form matches with high-skill workers - whose wages are higher than those of low-skill workers because of their higher productivity and higher outside option (employment in high-tech 
firms) - the expected gains from posting a low-tech vacancy are reduced. However, this effect is partially offset by the fact that low-tech firms encounter suitable job candidates faster as a result of high-skilled participation in the market for low-tech jobs. All told, lowtech vacancies decline, but by less than high-tech vacancies, making the share of low-tech vacancies in the total vacancy pool, $\phi_{L}$, rise. Since low-skilled workers find jobs at effective rate $\phi_{L} f$, the unemployment rate for low-skilled workers declines nearly twice as much as the unemployment rate for high-skilled workers. Moreover, given their higher job-finding prospects, wages for low-skilled workers increase modestly as firms must compensate them for their higher outside option.

All told, these results suggest that a trade liberalization that results in increased offshoring of high-skilled labor generates clear distributional effects in the Northern economy. It flattens the wage distribution as wages in the high-tech sector fall sharply while wages in the low-tech sector increase modestly. ${ }^{7}$ Unemployment is lower across the board, but the impact is greater for low-skilled individuals.

In the Southern economy, the shift from autarky to trade results in an increase in both the aggregate wage and aggregate unemployment. Since higher-skilled workers are now only willing to accept offshore (high-tech) jobs, low-tech firms in the Southern economy encounter suitable workers less frequently, which raises expected vacancy-posting costs. Consequently, low-tech vacancies $v_{L}^{*}$ decline resulting in a substantial increase in the low-skill unemployment rate, $u_{L}^{*} / \psi^{*}$ and a decline in the Southern low-tech wage $w_{L}^{*}$. In turn, the combination of Southern higher-skilled workers only being willing to accept offshore jobs in conjunction with the limited offshore vacancies posted by the multinational is such that the unemployment rate of higher-skilled Southern workers $u_{H}^{*} /\left(1-\psi^{*}\right)$ rises. However, since the value of offshore production is substantially higher than that of low-tech firms, the average wage of high-skilled workers under trade $\bar{w}_{H}^{*}$ is much higher than their autarky wage.

\footnotetext{
${ }^{7}$ In related work, Arseneau and Epstein (2014b) introduces on-the-job search to the present framework here to better understand the response of the wage distribution to an increase in offshoring. This approach is closely linked to Burdett and Mortensen (1998), Mortensen (2005), and Dolado, Jansen, and Jimeno (2009) and is supported empirically by Christensen, et. al. (2005).
} 


\subsection{The Role of Mismatch}

We conduct a simple experiment that allows us to parse out the direct role of mismatch in the adjustment of the Northern labor market to increased offshoring: Panel C of Table 2 shows results from the model assuming that the North stays in EPS equilibrium post-liberalization as opposed to switching to CSM equilibrium as in Panel B. Considering this third case allows us to shut down the equilibrium shift that is central to the results presented in the previous subsection as well as the results presented in DMS.

Comparing Panel C to Panel B makes it clear that if the Northern economy remains in EPS equilibrium, wages are significantly lower and unemployment is markedly higher following the trade liberalization. We conclude that the role of mismatch is to substantially mitigate the impact of offshoring on the labor market.

Intuitively, the benefit of mismatch comes from the fact that it allows for sectoral reallocation of the labor market following a large shock. In other words, mismatch opens up a number of additional employment opportunities for high-skilled individuals that would otherwise evaporate following the increase in offshoring. As high-skilled individuals take advantage of these opportunities, labor market activity shifts across sectors in a way that cushions the decline in wages and ultimately decreases unemployment. In absence of the ability to engage in this sectoral reallocation, the Northern labor market is fully exposed to the offshoring shock because the low- and high-tech labor markets are effectively segmented.

The role of mismatch in adjusting to trade liberalization in our model echoes earlier results by Albrecht and Vroman (2002) who examine the response to skill biased technological change in a closed economy setting. This may not be surprising as an offshoring shock can be thought of as a form of skill biased technological change in the sense that the reduction in trade costs changes the production frontier of the multinational by making offshoring possible.

\section{Sensitivity Analysis}

We conduct two sets of sensitivity analyses. The first focuses on how the characteristics of the multinational's production function shape the response of the labor market to an increase in 
offshoring. The second set focuses on the size of the parameter space that supports mismatch as an equilibrium outcome.

\subsection{The Multinational's Production Function}

By introducing a final goods producing firm that uses a flexibly parameterized CES aggregator, our model allows international linkages to play a wide role in shaping results. We examine the sensitivity of labor market outcomes to the size of the offshore sector and to the complementarity versus substitutability of Northern and Southern inputs in the multinational's production function.

\subsubsection{Size of Offshore Sector $(\eta)$}

Figure 1 shows labor market outcomes following a trade liberalization that results in a switch from an autarky EPS equilibrium to a trade CSM equilibrium (upper and lower panels on the left) and from an autarky EPS equilibrium to a trade EPS equilibrium (upper and lower panels on the right). In each case, the top panels present results for the unemployment rate and the bottom panels present results for the wage. Each panel is constructed by varying the share of offshored production in the high-tech good, $\eta$ (shown on the x-axis), while holding all other parameters of the model constant.

The figure shows that the baseline results are relatively insensitive to changing the offshoring share parameter. When the increase in offshoring induces a shift from EPS to CSM equilibrium, the upper and lower panels in the left column show that aggregate unemployment decreases and aggregate wages fall sharply regardless of the parameterization for $\eta$. Similarly, the upper and lower panels in the right column show that when the economy remains in EPS equilibrium, the unemployment rate rises rather than falls, and wages decline

even more sharply. Overall, these results are qualitatively similar to the baseline results and suggest that the equilibrium shift, rather than the specific parameterization of the production function, is much more important in determining the response of the labor market. 


\subsubsection{Complementarity vs. Substitutability $(\sigma)$}

Figure 2 conducts a similar exercise as in Figure 1, but now we vary the complementarity versus substitutability of Northern and Southern inputs in the multinational's production function, only. Compared to the case in which we varied $\eta$, changes in $\sigma$ yield a story that is a bit different. The panels in Figure 2 show that the baseline results are robust provided Northern and Southern inputs are sufficiently complimentary (i.e., $\sigma$ is sufficiently negative). But, as the two become more substitutable the effect on the labor market - and, in particular, unemployment - is quite different. For example, when the increase in offshoring induces a shift from EPS to CSM equilibrium, the upper left panel shows that this change drives an increase in low-skilled unemployment for low levels of complementarity. It is also interesting to note that the parameter space over which CSM equilibrium is supported does not exist for values of $\sigma$ above -4.4 (the shaded region in the figure's two panels). In the next subsection we investigate this existence aspect of the model more closely. The shift from EPS equilibrium in autarky to CSM trade equilibrium shows that when Northern and Southern labor are substitutable, there is a minimal impact of unemployment and the adverse effect of the high-tech wage is notably dampened.

\subsection{How General a Result is Equilibrium Mismatch?}

Our main results illustrate the importance of whether or not mismatch is a feature of the post-liberalization equilibrium for how the labor market adjusts to offshoring. Implicit is the fact that in our baseline parameterization both EPS (no mismatch) and CSM (mismatch) equilibrium are feasible. How general a result is the coexistence of both types of equilibria under trade?

Figure 3 offers some perspective on this. Holding constant all other parameters, the figure varies the share of offshored production in the high-tech good, $\eta$, along the $\mathrm{x}$-axis and the parameter governing the substitutability of Northern and Southern high-skilled inputs, $\sigma$, along the y-axis. Every point on the grid evaluates the conditions presented in Section 5.2 that tell us whether CSM equilibrium can obtain alongside EPS equilibrium.

The figure is divided into two regions. The (larger) shaded region to the left denotes that 
part of the parameter space in which both EPS and CSM equilibrium coexist. The unshaded (smaller) region to the right denotes that part of the parameter space where mismatch cannot be supported in a trade equilibrium. Finally, the black line denotes that baseline share parameterization of $\eta=0.9$. The baseline substitutability parameter has $\sigma$ such that Northern and Southern high-skilled inputs are strong complements in the multinational's production function, putting the baseline model in a part of the parameter space where both equilibria coexist and mismatch is feasible.

What is interesting about Figure 3 is that an empirically relevant parameterization is one in which the share of offshored production is relatively small, so that $0.9 \leq \eta<1$ (see, for instance, Burstein, Kurtz, and Tesar (2008) and Arseneau and Leduc (2012)). Within that range, mismatch only exists as an equilibrium outcome when domestic and foreign high-skilled inputs are sufficiently complementary. While our parameterization of $\sigma$ satisfies this criteria, there is considerable uncertainty regarding whether offshored production should be viewed as a complement to or a substitute for domestic inputs. Figure 1 suggests that if one believes the inputs are substitutes (or mild complements with a sufficiently low share of offshore activity), the labor market implications of offshoring could be much larger because mismatch will not arise to help cushion the labor market effects following a trade liberalization.

\section{Conclusion}

We study the role of mismatch in the adjustment of the labor market to a trade liberalization that results in offshoring of high-tech production. Our results suggest that mismatch helps to mitigate the negative labor market consequences that arise from offshoring. The ability to reallocate domestic high-skilled labor across both high- and low-tech industries dampens the increase in the unemployment rate as well as the decline in wages that result from shifting domestic production abroad. Our analysis also reveals that under our calibration the size of the parameter space over which mismatch can arise as an equilibrium outcome is, in fact, quite limited. Indeed, as long as the share of the offshored production is not too large, highskilled workers will only choose to accept jobs with low-tech firms if domestic and offshore 
high-tech production are sufficiently complementary.

In general, we view the limited subset of the parameters space in which mismatch can arise as an equilibrium outcome as a limitation of the model presented in this paper. in order to bring a calibrated version of the model more in line with observed data, the model needs to be extended in a way that makes mismatch a more attractive proposition to both workers and firms following trade reform. We pursue two such extensions in companion work. Arseneau and Epstein (2014b) introduces on-the-job search to the partial equilibrium framework presented here, while Arseneau and Epstein (2014c) extends this modeling framework to a general equilibrium open economy setting with endogenous directed search.

\section{References}

[1] Acemoglu, Daron, Gino Gancia, and Fabrizio Zilibotti (2012). "Offshoring and Directed Technical Change." No. w18595. National Bureau of Economic Research.

[2] Albrecht, James, and Susan Vroman (2002). "A Matching Model with Endogenous Skill Requirements." International Economic Review, 43(1), 283-305.

[3] Amiti, Mary and Shang-Jin Wei (2005). "Fear of Services Offshoring: Is it Justified?" Economic Policy, 20(42), 208-347.

[4] Arseneau, David M. and Brendan Epstein (2014a). "The Welfare Costs of SkillMismatch Employment." Finance and Economics Discussion Series 2014-42, Board of Governors of the Federal Reserve System.

[5] Arseneau, David M. and Brendan Epstein (2014b). "On-the-Job Search and Mismatch in a Model of Offshoring." Mimeo, Federal Reserve Board of Governors.

[6] Arseneau, David M. and Brendan Epstein (2014c). "Offshoring and Job Dislocation." Mimeo, Federal Reserve Board of Governors.

[7] Arseneau, David M. and Sylvain Leduc (2012). "Threatening to Offshore in a Search Model of the Labor Market." Mimeo, Federal Reserve Board of Governors.

[8] Blinder, Alan. 2009. "How Many U.S. Jobs Might be Offshorable?" World Economics, $10(2), 41-78$.

[9] Bosch Mossi, Mariano, and William F. Maloney (2007). "Gross Worker Flows in the Presence of Informal Labor Markets: Evidence from Mexico, 1987-2002." Mimeo. 
[10] Burdett, Kenneth, and Dale T. Mortensen (1998). "Wage Differentials, Employer Size, and Unemployment." International Economic Review, 39, 257-273.

[11] Burstein, Ariel, Christopher Kurz, and Linda Tesar (2008). "Trade, Production Sharing, and the International Transmission of Business Cycles." Journal of Monetary Economics, 55(4), 775-795.

[12] Christensen, Bent Jesper, Rasmus Lentz, Dale T. Mortensen, George R. Neumann, and Axel Werwatz (2005). "On-the-Job Search and the Wage Distribution." Journal of Labor Economics, 23(1), 31-58.

[13] Costinot, Arnaud and Jonathan Vogel (2010), "Matching and Inequality in the World Economy." Journal of Political Economy, 118(4), 747-786.

[14] Crino, Rosario (2009). "Offshoring, Multinationals, and Labour Market: A Review of the Empirical Literature." Journal of Economic Surveys, 23(2), 197-249.

[15] Davidson, Carl and Steven J. Matusz (2009). International Trade with Equilibrium Unemployment. Princeton University Press, Princeton, N.J.

[16] Davidson, Carl, Steven J. Matusz, and Andrei Shevchenko (2008). "Outsourcing Peter to Pay Paul: High-skill Expectations and Low-Skill Wages with Imperfect Labor Markets." Macroeconomic Dynamics, 12, 463-479.

[17] Diamond, Peter A (1982). "Wage Determination and Efficiency in Search Equilibrium." The Review of Economic Studies, 49(2), 217-227.

[18] Dolado, Juan J., Marcel Jansen, and Juan F. Jimeno (2009). "On-the-job Search in a Matching Model with Heterogeneous Jobs and Workers." The Economic Journal $119,200-228$.

[19] Ebenstein, Avraham Y., Ann E. Harrison, Margaret S. McMillian, and Shannon Phillips (2011). "Estimating the Impact of Trade and Offshoring on American Workers Using the Current Population Surveys." No. w15107. National Bureau of Economic Research.

[20] Elsby, Michael W. L., Ryan Michaels, and Gary Solon (2009). "The Ins and Outs of Cyclical Unemployment." American Economic Journal: Macroeconomics, 1(1), 84110.

[21] Epstein, Brendan (2012). "Heterogeneous Workers, Optimal Job Seeking, and Aggregate Labor Market Dynamics." International Finance Discussion Papers 1053, Board of Governors of the Federal Reserve System. 
[22] Feenstra, Robert C. and Gordon H. Hanson (1996). "Globalization, Outsourcing and Wage Inequality." American Economic Review 86(2), 240-245.

[23] Feenstra, Robert C. and Gordon H. Hanson (1997). "Foreign direct investment and relative wages: evidence from Mexico's Maquiladoras." Journal of International Economics, 42(3-4), 371-393.

[24] Feenstra, Robert C. and Gordon H. Hanson (1999). "The Impact of Outsourcing and High-Technology Capital on Wages: Estimates for the United States, 1979-1990." Quarterly Journal of Economics, 114(3), 907-940.

[25] Feenstra, Robert C. and Gordon H. Hanson (2003). "Global Production Sharing and Rising Inequality: A Survey of Trade and Wages." In K. Choi and J. Harrigan (eds), Handbook of International Trade (pp. 146-185). Oxford: Blackwell.

[26] Gautier, Pieter A (2002). "Unemployment and Search Externalities in a Model with Heterogeneous Jobs and Workers." Economica, 69(2), 21-40.

[27] Goos, Maarten, Alan Manning, and Anna Salomons (2011). "Explaining Job Polarization: The Roles of Technology, Globalization, and Institutions," University of Leuven Working Paper.

[28] Gorg, Holger and Aoife Hansely (2005). "Labour Demand Effects of International Outsourcing: Evidence from Plant-level Data." International Review of Economics and Finance, 14(3), 365-376.

[29] Grossman, Gene M. and Esteban Rossi-Hansberg (2008). "Trading Tasks: A Simple Theory of Offshoring." American Economic Review, 98(5), 1978-1997.

[30] Helpman, Elhanan (2006). "Trade, FDI, and the Organization of Firms." Journal of Economic Literature, 44(4), 580-630.

[31] Hosios, Arthur J. (1990). "On the Efficiency of Matching and Related Models of Search and Unemployment." Review of Economic Studies, 57(2), 279-298.

[32] Hummels, David, Jakob R. Munch, and Chong Xiang (2011). "Offshoring, Transition, and Training: Evidence from Danish Matched Worker-Firm Data." American Economic Review: Papers and Proceedings, 102(3), 424-428.

[33] Jacobson, Louis S., Robert J. Lalonde, and Daniel J. Sullivan (1993). "Earning Losses of Displaced Workers." American Economic Review, 83(4), 685-709.

[34] Kletzer, Lori (2001). "What Are the Costs of Job Loss from Import-Competing Industries?" Washington, DC: Institute for International Economics. 
[35] Liu, Runjua and Daniel Treffler (2008). "Much Ado About Nothing: American Jobs and the Rise of Service Offshoring to China and India." No. w14061. National Bureau of Economic Research.

[36] Mitra, Divashish and Priya Ranjan (2010). "Offshoring and Unemployment: The Role of Search Frictions and Labor Mobility." Journal of International Economics, 81(2), 219-229.

[37] Mortensen, Dale T. (1982). "Property Rights in Mating, Racing, and Related Games." American Economic Review 72(5), 968-79.

[38] Mortensen, Dale T. and Christopher A. Pissarides (1994). "Job Creation and Job Destruction in the Theory of Unemployment." The Review of Economic Studies, 61(3), $397-415$.

[39] Mortensen, Dale T. and Christopher A. Pissarides (1999). "Unemployment Responses to 'Skill-Biased' Technology Shocks: The Role of Labour Market Policy." The Economic Journal, 109(455), 242-265.

[40] Mortensen, Dale T. (2005). "Wage Dispersion: Why are Similar Workers Paid Differently?" Cambridge MA: MIT Press.

[41] Oldenski, Lindsay (2014). "Offshoring and the Polarization of the U.S. Labor Market." Industrial and Labor Relations Review, 67, Supplement.

[42] Petrongolo, Barbara, and Christopher A. Pissarides (2001). "Looking into the Black Box: A Survey of the Matching Function." Journal of Economic Literature, 39(2), 390-431.

[43] Ranjan, Priya (2013). "Offshoring, Unemployment, and Wages: The Role of Labor Market Institutions." Journal of International Economics, 89(1), 172-186.

[44] Shimer, Robert (2005). "The Cyclical Behavior of Equilibrium Unemployment and Vacancies." American Economic Review, 95(1), 25-49.

[45] Shimer, Robert (2012). "Reassessing the Ins and Outs of Unemployment." Review of Economic Dynamics, 15(2), 127-148.

[46] Sicherman, Nachum (1991). "Overeducation in the Labor Market." Journal of Labor Economics, 9, 101-112. 
Table 1: Baseline Calibration at Monthly Frequency

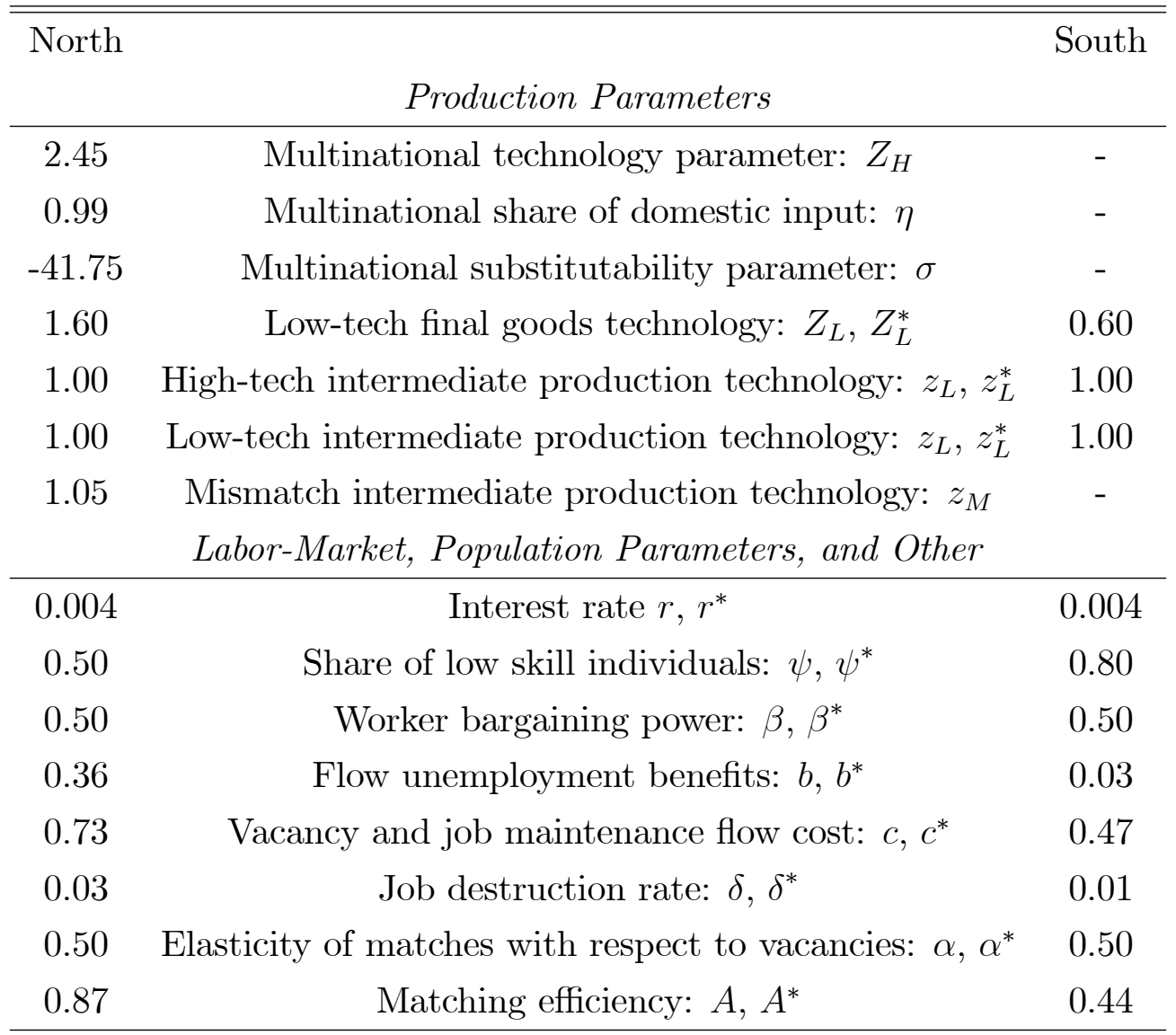




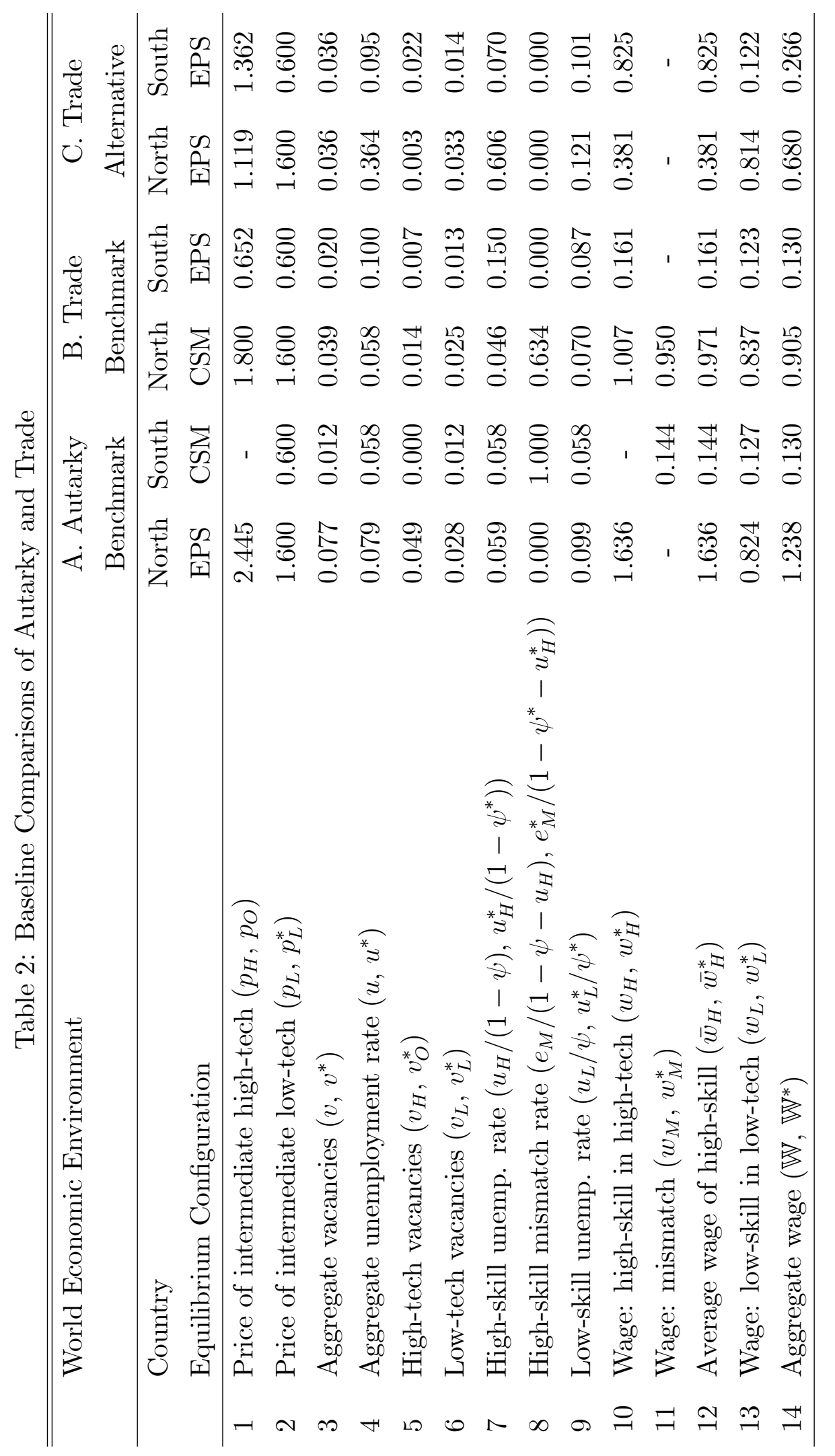


Percentage Point Change in Unemployment Rates: Autarky (EPS) to Trade (CSM)

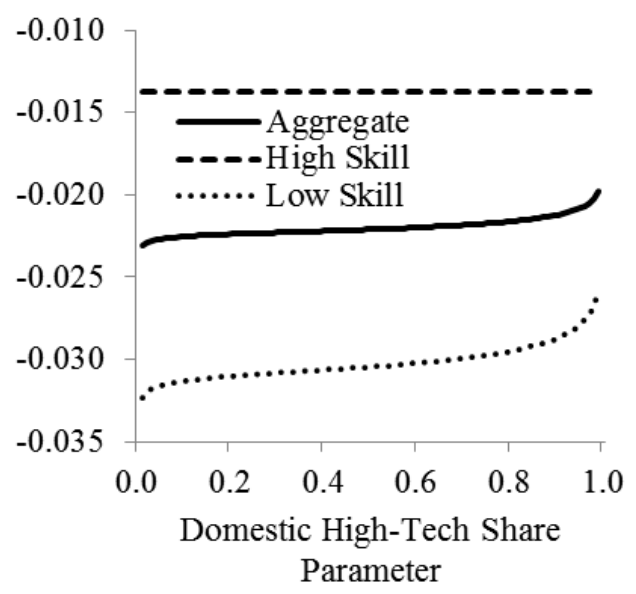

Percent Change in Wages: Autarky (EPS) to Trade (CSM)

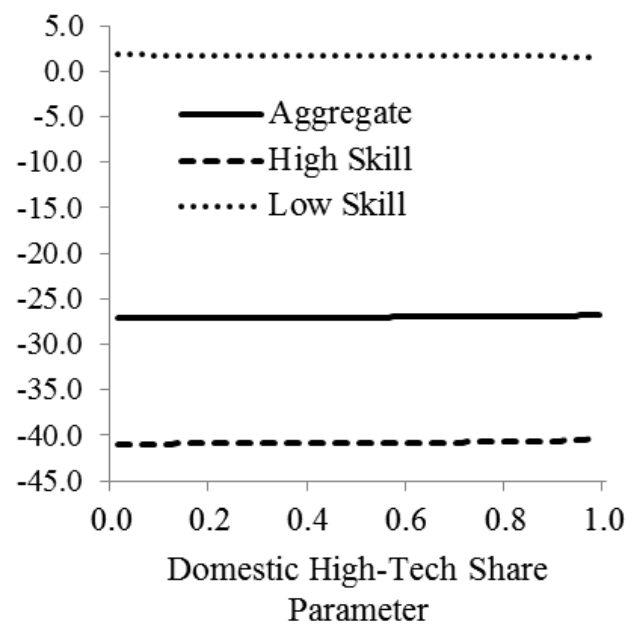

Percentage Point Change in Unemployment Rates: Autarky (EPS) to Trade (EPS)

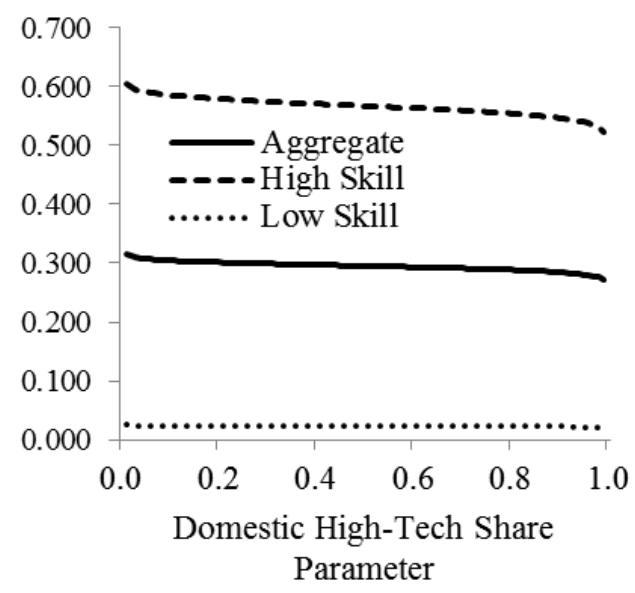

Percent Change in Wages: Autarky (EPS) to Trade (EPS)

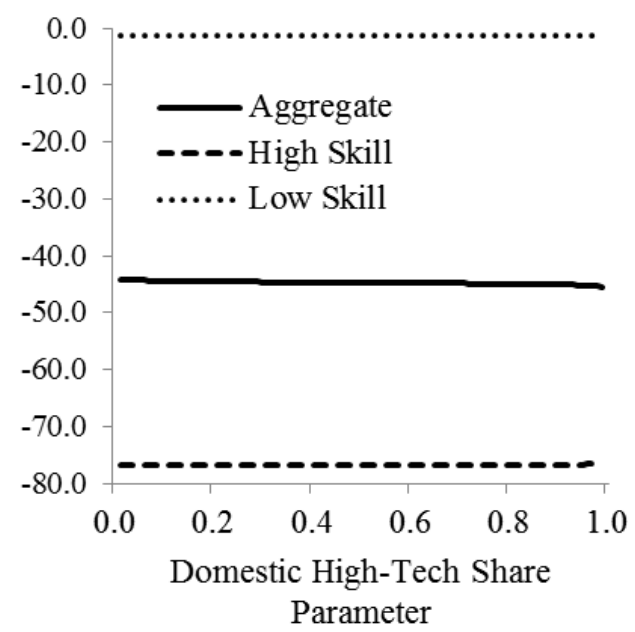

Figure 1: Sensitivity of labor market outcomes to share of offshoring in multinational production function. 
Percentage Point Change in Unemployment Rates: Autarky (EPS) to Trade (CSM)

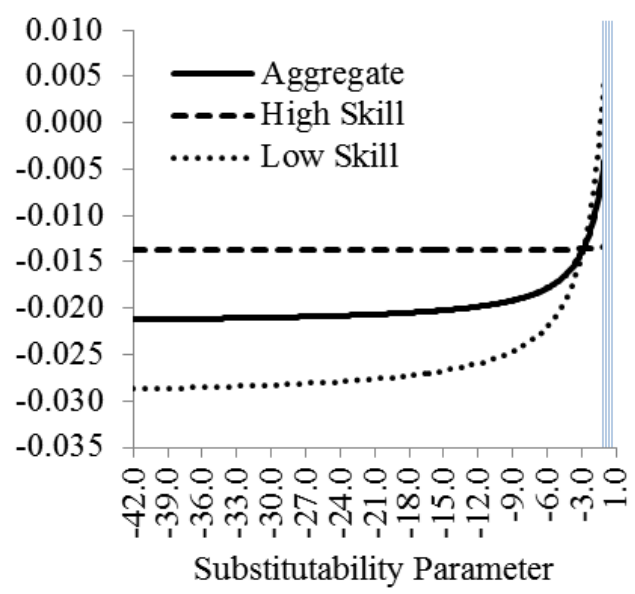

Percent Change in Wages: Autarky (EPS) to Trade (CSM)

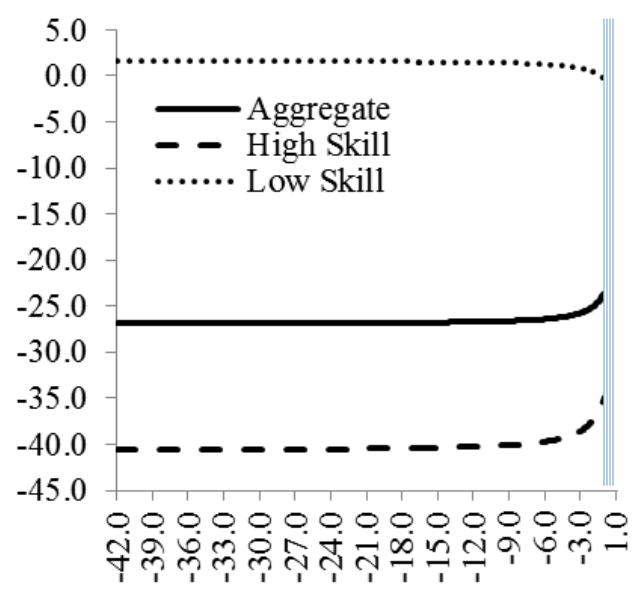

Substitutability Parameter
Percentage Point Change in Unemployment Rates: Autarky (EPS) to Trade (EPS)

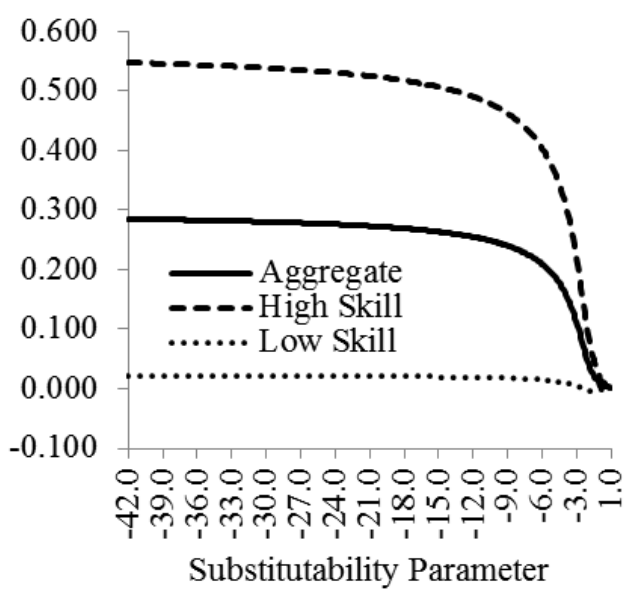

Percent Change in Wages: Autarky (EPS) to Trade (EPS)

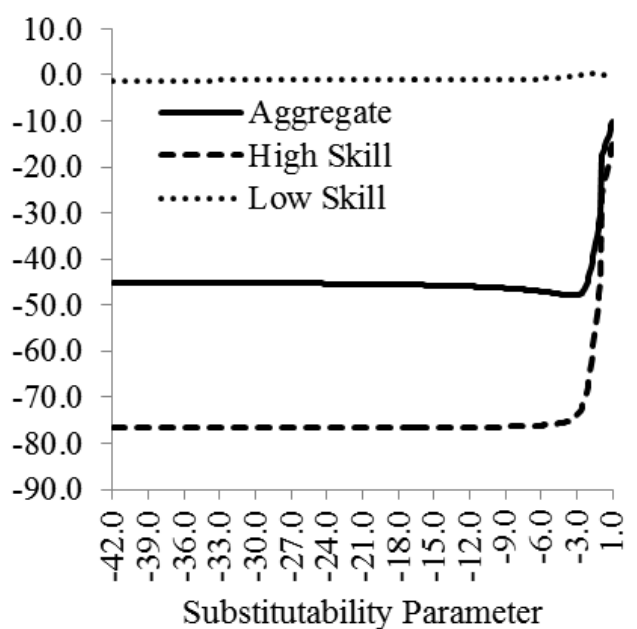

Figure 2: Sensitivity of labor market outcomes to input substitutability parameter in multinational production function. 


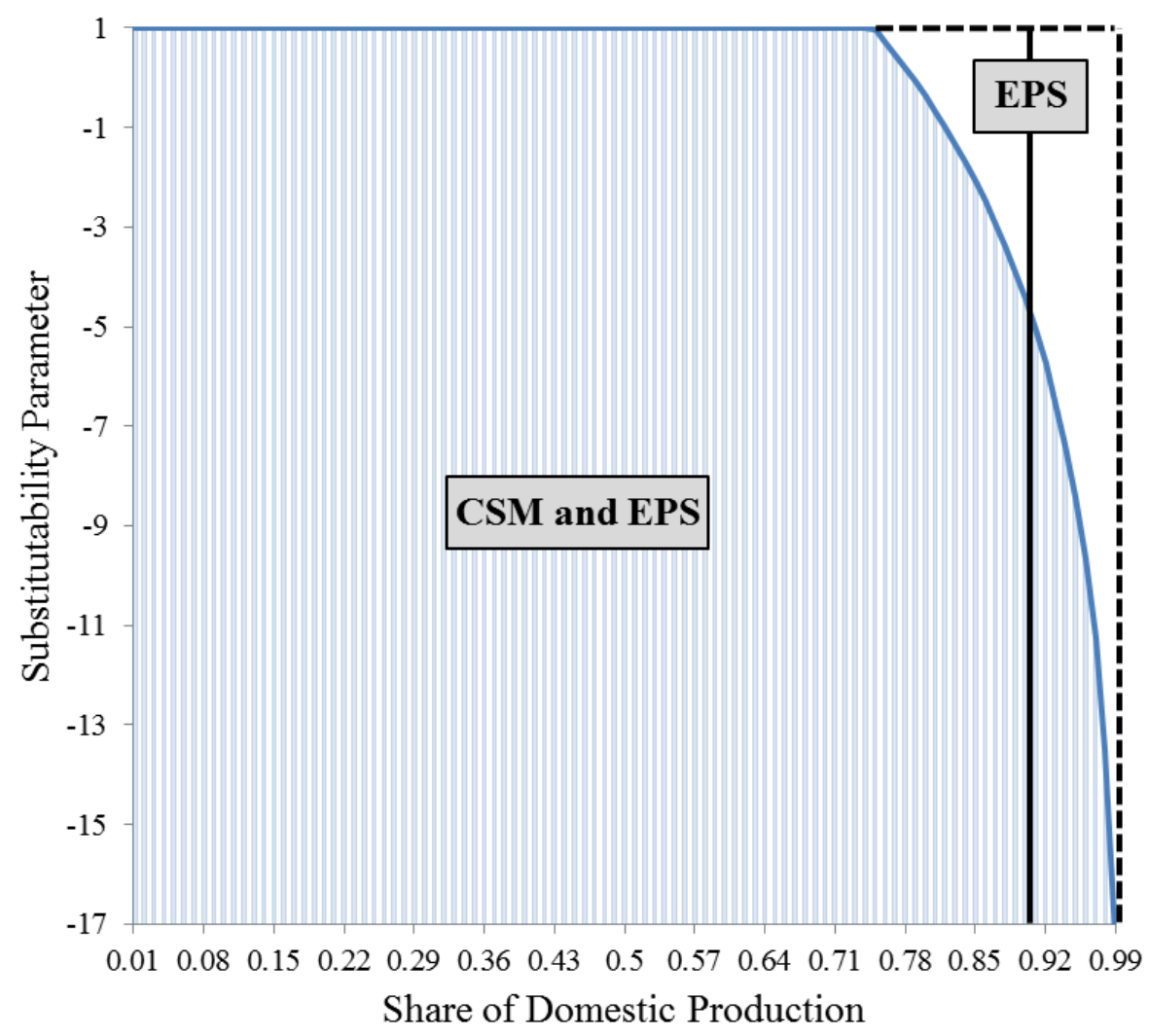

Figure 3: Existence of CSM and EPS equilibriums (substitutability and share of offshoring). 